\title{
A Legal Study of the Rights of Privacy
}

\author{
Dr.Abdalrazak Alsheban \\ Faculty of Law/Cihan University / Sulaymaniyah
}

\begin{abstract}
Law is in charge of protecting humans from any assault, aggression or attack and particularly the physical or moral one. The right of privacy is one of the elements of the moral entity of humans. Consequently, law is in charge of protecting such privacy. The right of privacy comprises various kinds of human rights like the confidentiality of personal life, the privacy of relationships and so on. Such privacy may be violated through various ways including eavesdropping, watching, spying and other means which people do not feel satisfied with at all. The current paper aims at illustrating in detail the right of privacy as an essential part of the rights that all humans must enjoy. In addition, it shows the various ways through which the right of privacy might be violated with reference to some situations.
\end{abstract}

Key words :Privacy, confidentiality, correspondence, conversations, image, analgesic, secrets, recording, satisfaction, Media, Publishing.

\section{i. INTRODUCTION}

Humans always seek maintaining the moral entity of reputation which is regarded as the inviolability of privacy. Such privacy is considered so due to the fact that the violation of the reputation or any other sensitive case which is peculiar to the personal life of humans will result into negative impact of prejudice. Underlining the importance of the right to privacy, it has been stated by the domestic legislation and the majority of international agreements, as Article 12 of the Universal Declaration of Human Rights states that "It is not permitted that one is exposed to arbitrary interference in his privacy, personal life or any other sensitive case. Everyone has the right to be protected by law against such interference or in such cases. In addition the first paragraph of Article 8 of the European Convention on human rights, signed in Rome on 4 / November / 1950, stated that everyone has the right of being respected at the essential levels of life including respecting the personal life and all kinds of relationships which are peculiar to humans( Saleh,1993:184).

\section{ii. DEFINITION OF THE RIGHT TO PRIVACY}

Despite the recognition of the comparative legislation of the right of privacy, no one included what the right of privacy is and this prompted the Jurists diligence to determine the meaning of the right to privacy. The American Law Institute defined the right of privacy as: "Every person who violates seriously and unjustly the right of anyone else in the conditions of its affairs and do not relate to the knowledge of others, and not be susceptible to image the public eye, is answerable to the victim as". (Ahwani.H. 1978: 47)There is also a tendency in France doctrinal leaning upon definition of the right to privacy to the link between him and the concept of freedom, where the right to privacy is known as "the total number of cases, business and the views of the individual freedom which are not linking any obligation in the face of others."( Bahar. M.1983:190).In Iraq, the overall trend is the lack of doctrinal studies relating to personal rights and is valid to say the right to privacy, in the field of civil Jurists, this right is often addressed him as one of the images of moral damage, which means his studies in secondary without legal system his statement.

\section{iii. THE CONTENT OF THE RIGHT TO PRIVACY}

Under the term implies the right to privacy of an unspecified number of can be increased and decreases rights, Control as the place where multiple factors, for example, in France is edema financial personThe most important peculiarities of the individual. While in America are deployed regard to financial disclosure permanently And regular. That means trouble inventory components of the right to privacy and that The instability of this idea, which had differing views toward significant impact on the lack of stability. ( Ahwani. H. 1978:49) 


\section{The right to secrecy}

The secret is what stifles In legal terminology is keep the news as confidential. Even if aware of it more than one person, provided that the number of people with limited worlds. There is no limit to the number of people who have kept him in the news with their knowledge secret are linked Secret idea of the idea of the right to privacy closely linked to the extent that the judiciary may Jurists Face their interest towards the recognition of the right to confidentiality of the right to privacy Before addressing the issue of the right to be respected.( Bahar. M.1983:129).

\section{The right to cellular}

The right to privacy, is defined as "an individual's right to determine himself what he shares with others in his thoughts and his emotions and facts relating to his private life,". Learned from this definition that the meaning of the right to privacy, is the individual's right to live part of his life. At least in isolation from the others involve himself away from publicity lights. This statement is not inconsistent with the fact that man is a social being by nature can not live without the group. Not over-exaggeration of the human social must be given the right to privacy, himself and away from the social circle of life.( Ahwani. H. 1978:5).

\section{Right to privacy of correspondence and conversations and personal facts for}

The correspondence of any kind "physical translation of the ideas of the person is not allowed to is the sender or sent to him access to their content and only count it a violation of the sanctity of the mail and therefore a violation of the right to privacy. So the sanctity of the mail is one of the important right to privacy elements, The message may be a repository the mystery of man and his privacy. Which is keen to hide it from third parties and therefore to see it a waste of the most important rights which is guaranteed under the law to protect "( Bahar. M.1983:248).

\section{iv. Types prejudice to the right to privacy}

The relative instability is not limited to the definition of the content and scope of the right to privacy. But also included pictures prejudice that right and therefore difficult to limit these images. Which are constantly increasing commensurate with the scientific development in ways that make it easier to spy on others, and generally. The prejudice to the right to privacy occurs through the senses of hearing. Consider whether it is done by using the senses alone or were to benefit from the results of scientific advances and techniques in this field. Will be a statement by displaying pictures prejudice of this right by the stages of their occurrence.

\section{Eavesdropping and peeking}

Go preponderant opinion in civil Jurists that the mere eavesdropping, even if with permission only. Without the use of means of infringing the right to privacy regardless of the content of the talk that has been hearing. Merely parking the person behind the door to hear what is going on at home is a violation of the right to privacy. But the problem in this case it lies in the difficulty of proving the assault (Kadhim. S, 1975:26).

\section{Record conversations, take pictures or transferred and photographing correspondence content}

The mere eavesdropping and peeking through the naked senses infringing on the right to privacy. But could face doing so obstacles as if it were the place to be stalking him exposed so difficult to approach and hear or see what is going on it is not ministering to do so using traditional means as Endoscope and magnifier as if he was surrounded by dense trees. In such cases are stalking the use of modern techniques that put in place and the transfer of scenes and conversations that take place in it and send it to another place where there are received using other devices dedicated to it. Defines the modern transfer as a "transfer of the place in which they are to another place," The transfer of the image is "put devices enables voyeur to see what is going on elsewhere, such as the development of closed-circuit television".( Ahwani. H. 1978:5).

\section{Publish the content of the conversations, pictures and correspondence}

The consent of the person logged conversations or take a picture of him does not mean giving the right to those who have been satisfaction for him that the announcement of what he saw or heard or published. But must get permission stakeholders to do so. Otherwise they can resort to the judiciary to protect their rights, and not prejudice these rights in accordance with prior methods after one of the two phases of the two previous attacks. Meaning that a deployment to be either sayings and pictures have been found or recorded. As is the publication of the above either orally and by whatever means Speaking in privacy on the filling of people in a public place so that the publicity required realized to consider the act a violation of privacy as realized this publicity if Published by television. Which is realized for interviews and images, or by radio fundamental ways ( Ahwani. H. 1978:133). 


\section{v. Restrictions that are set on the right to privacy}

There are several restrictions are set on the right to privacy, including:

\section{Satisfaction as the reason for the legality of compromising privacy}

It can be compromising the right to privacy by hiring the right holder paid or free of charge. According to the general rules stops and there is compromise on the convergence of the expression of the direction of two wills to contracting and their association and of alignment and this in turn requires the issuance offers contract and accept him on their association and of alignment. ( Ahwani. H. 1978:305)

\section{The right to notification}

The press is a very important role in the life which is to inform the public on what is going on around him of events and inform them of the various news and in various fields to help in the formation of public opinion on various issues and this is what is called the right to information. Which is a restriction on the right to privacy because it includes a presentation the departments has opposing first the public interest in knowing what is going on from things and events. The second is the individual's interest in maintaining the right to privacy and due to the importance of each of the right to information and right to privacy. It is difficult to give priority to one over the other account, where you must take into account the right to privacy in exercising the right to information (Jubouri. S, 2000:82 ). Requires Jurists passport deployment affects the right to privacy, the availability of the following conditions:

a. That news is true.

B. Be news related to an incident of public interest.

C. Publication may be obtained in good faith.

\section{vi. CONCLUSION}

The right to privacy is one of the personal rights and includes several issues the most important, the right to secrecy is to keep the person his input own secrets, right in the cellular and the right to determine what is shared with others in his thoughts and his emotions and facts relating to his private life, and away from the social circle of life, and the right the person in the sanctity of correspondence and conversations and personal facts own, and the right to live in his private residence without being seen by others. The most important pictures prejudice to the right to privacy, eavesdropping and voyeurism, taking pictures and publish, and publish the content of the mail. Nevertheless, there are limitations to respond to protect the right to privacy, the most important deployment issues related to privacy with the consent of the person in the media and the dissemination of correct news related to the facts of public interest, and to be published in good faith.

\section{REFERENCES:}

[1] Ahwani. Hossam El Din Kamel (1978). The Right to Respect for Private Life, Cairo, Dar Al Arab renaissance.

[2] Saleh. RafeKhadr (1993). The Right to Privacy and Guarantees in the face of Computer uses, Master Thesis, Faculty of Law, University of Baghdad.

[3] Jubouri. Saad Saleh Hkta (2000).ResponsibilityJournalistCriminalfor crimes Publishing, Master Thesis, Faculty of Law, University of Mosul.

[4] Kadhim. Saleh Jawad (1975) Modern Technology and Personal Confidentiality, Journal of Arab Studies, No. 8.

[5] Bahar. Mamdouh Khalil (1983). The Protection of Private Life in Comparative Law, Arab Renaissance Publishing House, Cairo. 